\title{
Managing comorbidities in idiopathic pulmonary fibrosis
}

This article was published in the following Dove Press journal:

International Journal of General Medicine

22 September 2015

Number of times this article has been viewed

\author{
Blair G Fulton' \\ Christopher J Ryerson ${ }^{1,2}$ \\ 'Department of Medicine, ${ }^{2}$ Centre \\ for Heart Lung Innovation, University \\ of British Columbia, Vancouver, \\ BC, Canada
}

\begin{abstract}
Major risk factors for idiopathic pulmonary fibrosis (IPF) include older age and a history of smoking, which predispose to several pulmonary and extra-pulmonary diseases. IPF can be associated with additional comorbidities through other mechanisms as either a cause or a consequence of these diseases. We review the literature regarding the management of common pulmonary and extra-pulmonary comorbidities, including chronic obstructive pulmonary disease, lung cancer, pulmonary hypertension, venous thromboembolism, sleep-disordered breathing, gastroesophageal reflux disease, coronary artery disease, depression and anxiety, and deconditioning. Recent studies have provided some guidance on the management of these diseases in IPF; however, most treatment recommendations are extrapolated from studies of non-IPF patients. Additional studies are required to more accurately determine the clinical features of these comorbidities in patients with IPF and to evaluate conventional treatments and management strategies that are beneficial in non-IPF populations.
\end{abstract}

Keywords: interstitial lung disease, management, idiopathic pulmonary fibrosis, comorbidities

\section{Introduction}

Idiopathic pulmonary fibrosis (IPF) is a chronic progressive fibrotic interstitial lung disease (ILD) of unknown etiology. ${ }^{1}$ IPF has an estimated prevalence of 14-43 per $100,000^{2}$ and is the most common idiopathic interstitial pneumonia. The incidence of IPF appears to be increasing over time, even when accounting for an aging population and increased use of chest imaging. ${ }^{3,4}$

Major risk factors for IPF include older age and a history of smoking, which predispose to several pulmonary and extra-pulmonary diseases. IPF can be associated with additional comorbidities through other mechanisms as either a cause or a consequence of these diseases. These comorbidities have a significant impact in IPF given their additional physiologic and symptomatic effect on a background of underlying pulmonary fibrosis. The prevalence and importance of these comorbidities will likely be further increased by possible prolongation of survival in IPF by new antifibrotic medications. ${ }^{5}$

The objective of this review is to describe the management of common comorbidities in IPF. We review the available literature for several pulmonary and extra-pulmonary comorbidities, and make management recommendations based on available evidence where possible.
Correspondence: Christopher J Ryerson Paul's Hospital, 108I Burrard Street Ward 8B, Vancouver,

BC V6Z IY6, Canada

Fax +I 6048068839

Email chris.ryerson@hli.ubc.ca 


\section{Pulmonary comorbidities Emphysema}

Emphysema frequently coexists with IPF as "combined pulmonary fibrosis and emphysema" (CPFE), a clinical syndrome that is characterized by upper lobe emphysema and lower lobe fibrosis. Up to $50 \%$ of patients with IPF have radiological evidence of emphysema; ${ }^{6}$ however, only $10 \%$ of IPF patients have a clinically significant amount of emphysema (eg, $\geq 10 \%$ of lung volume). ${ }^{7}$ Patients with CPFE are often male former smokers with a diffusing capacity of the lung for carbon monoxide (DLCO) that is disproportionately reduced compared to relatively preserved flow rates and lung volumes. ${ }^{78-14} \mathrm{CPFE}$ is frequently associated with pulmonary hypertension and lung cancer in patients with IPF.,15,16 The prognosis of CPFE is primarily determined by the severity of fibrosis, and is similar to that for patients with IPF alone. ${ }^{7}$ Emphysema can be present in other fibrotic ILDs, ${ }^{14,17-21}$ but is typically less common and less severe than in IPF. Studies evaluating CPFE have used multiple definitions for CPFE, differing with regards to both how emphysema is quantified on computed tomography (CT) and how much emphysema must be present before a patient is considered to have both conditions. These different definitions of CPFE may account for the variability in prevalence, clinical features, and prognosis reported in these cohorts.

Patients with CPFE have been excluded from major clinical trials of both individual entities, and its treatment is therefore extrapolated from studies of these isolated diseases. Management of emphysema in IPF should typically include smoking cessation, pneumococcal and influenza vaccination, pulmonary rehabilitation, supplemental oxygen for hypoxemia, and consideration of lung transplantation. Bronchodilators are frequently prescribed in CPFE; however, it is unclear whether these are only beneficial in CPFE patients that have significant airflow limitation (ie, reduced forced expiratory volume in 1 second/forced vital capacity [FVC] ratio). The role of inhaled corticosteroids is uncertain given the increased risk of pneumonia associated with inhaled corticosteroids in chronic obstructive pulmonary disease (COPD), ${ }^{22}$ and the potential for pulmonary infection to trigger an acute exacerbation of IPF. Acute exacerbations of both COPD and IPF are frequently treated with systemic corticosteroids and antibiotics that target common community-acquired organisms, and these treatments are also reasonable in acute exacerbation of CPFE despite the absence of direct evidence. Systemic corticosteroids should be tapered quickly following an acute exacerbation, given the harm associated with chronic immunosuppression in stable IPF. ${ }^{23}$ Additional studies are required to determine the impact of both standard COPD and IPF treatments in patients with an overlap of these conditions.

\section{Lung cancer}

The risk of developing lung cancer is approximately seventimes higher in patients with IPF compared to a control population. ${ }^{24}$ This increased risk persists even with adjustment for age, sex, and smoking history, suggesting that the IPF lung is specifically predisposed to developing malignancy. Lung cancer often presents with nonspecific symptoms in IPF; however, hemoptysis, weight loss, and other constitutional symptoms should prompt further evaluation. The presence of lung cancer shortens survival by approximately 2 years in patients with IPF. ${ }^{25}$

The nonspecific symptoms and high mortality of lung cancer in IPF suggest a possible role for lung cancer screening in high-risk patients. The National Lung Screening Trial showed that annual low-dose CT reduced overall mortality by $6.7 \%$ in adults $55-74$ years old with at least a 30-pack-year smoking history, ${ }^{26}$ and such screening has since been recommended for this population. ${ }^{27}$ IPF reduces life expectancy and can prohibit potentially curative lung cancer therapy, and it is therefore unclear whether patients with IPF experience similar benefits to those observed in the National Lung Screening Trial. Screening for lung cancer may still be appropriate in IPF if identification of malignancy would alter management, including decisions to proceed with lung transplant or initiate palliative therapies.

IPF patients diagnosed with lung cancer are frequently not candidates for curative therapy given the low functional capacity in this population and decreased ability to tolerate cancer therapies. Management of lung cancer in IPF should therefore be approached on a case-by-case basis, balancing the likelihood of cure or effective palliation against the potential for treatment complications, and considering the overall poor prognosis of IPF. Patients with pulmonary fibrosis are at high risk of mortality following lung cancer resection. ${ }^{28}$ This increased risk is frequently secondary to acute exacerbation of IPF, which occurs in 5\%-15\% of IPF patients following thoracic surgical procedures and has a subsequent short-term mortality of approximately $50 \%{ }^{29-33}$ Radiation and chemotherapy can also precipitate acute exacerbation of IPF, with a similar poor prognosis. ${ }^{34-36}$ It is unknown whether acute exacerbation will be less common with improved ventilation strategies and surgical techniques, 
new chemotherapeutic agents, and lung-sparing stereotactic ablative radiotherapy.

\section{Pulmonary hypertension}

Pulmonary hypertension is present in approximately $50 \%$ of patients with IPF at the time of referral for lung transplantation. ${ }^{37-41}$ Pulmonary hypertension in IPF is likely due to multiple factors, including vasoconstriction induced by chronic hypoxia and the destruction of capillary beds by progressive fibrosis. Some IPF patients have pulmonary hypertension that appears disproportionate to fibrosis severity, ${ }^{37,38}$ suggesting additional mechanisms may be involved in a minority of patients.

Pulmonary hypertension can be difficult to identify in $\mathrm{IPF}^{42-44}$ but should be suspected in patients with dyspnea that is disproportionate to fibrosis severity; in patients with clinical findings of right heart dysfunction; and in patients with a reduced DLCO that is out of proportion to the reduction in FVC. ${ }^{38,40,45,46}$ Additional suggestive features include exercise limitation or desaturation that is disproportionate to fibrosis severity ${ }^{47-49}$ as well as markers of cardiac dysfunction (eg, abnormal heart rate recovery following exercise, B-type natriuretic peptide)..$^{40,48,50,51}$ IPF patients with suspected pulmonary hypertension typically undergo screening with a transthoracic echocardiogram; however, the poor accuracy of echocardiographic findings in ILD indicates that right heart catheterization is necessary to confirm pulmonary hypertension. Right heart catheterization may still be appropriate in patients with a high pretest likelihood of pulmonary hypertension even if echocardiography is reassuring. ${ }^{52}$ Once identified, it is necessary to exclude other causes of pulmonary hypertension that may respond to specific treatment (eg, obstructive sleep apnea [OSA], left heart disease, venous thromboembolism).

Pulmonary hypertension is associated with increased mortality in IPF, ${ }^{15,40-42,49,53-59}$ suggesting potential benefit of pulmonary vasodilators in these patients. Despite this rationale, multiple studies have demonstrated that endothelin receptor antagonists have no benefit in IPF, ${ }^{60-63}$ even when administered to patients with confirmed pulmonary hypertension. ${ }^{60,64}$ Sildenafil, a phosphodiesterase type 5 inhibitor, was compared to placebo in 180 patients with advanced IPF $^{65}$ This trial did not meet its primary endpoint (6-minute walk distance improvement of $\geq 20 \%$ ); however, sildenafil improved dyspnea, oxygenation, DLCO, and quality of life, with borderline impact on survival in the extension phase of this study. Additional post hoc analyses have suggested greater benefit in patients with echocardiographic evidence of right heart dysfunction. ${ }^{66}$ These findings indicate that further research is required to determine whether there is a role for sildenafil in IPF patients that have more definitive evidence of pulmonary hypertension.

\section{Venous thromboembolism}

Patients with IPF are at increased risk for venous thromboembolism due to decreased mobility causing venous stasis, ${ }^{67}$ as well as possible involvement of the coagulation cascade in IPF pathogenesis. ${ }^{68,69} \mathrm{IPF}$ patients with pulmonary embolism are at increased risk of death. ${ }^{70}$ Venous thromboembolism contributed to $1.74 \%$ of all IPF deaths based on a review of death certificates in the United States between 1988 and $2007 .{ }^{70}$ This rate was 34\% higher than in the general population, and approximately 50\% higher than in patients with COPD and lung cancer. Venous thromboembolism is similarly linked with IPF in multiple European cohorts. ${ }^{71-73}$

Venous thromboembolism can be challenging to identify in patients with IPF given its nonspecific presentation in patients with chronic and progressive lung disease. Pulmonary embolism is of particular concern in patients with acute exacerbation of IPF, typically prompting evaluation with contrast $\mathrm{CT}$ in patients with acute or subacute respiratory worsening. Conversely, contrast CT may identify subsegmental filling defects that are of uncertain significance in patients with severe fibrosis, and careful consideration of the clinical context is required before committing a patient to long-term anticoagulant therapy.

An early randomized trial suggested that warfarin improved overall survival of IPF by lowering the risk of death in patients experiencing an acute exacerbation. ${ }^{74}$ Criticisms of this study prompted the ACE-IPF study, ${ }^{75}$ which was a double-blind placebo-controlled trial of warfarin in patients with progressive IPF who had no other indication for anticoagulation. ${ }^{76}$ ACE-IPF showed that warfarin increased mortality in progressive IPF and that there were no significant benefits of therapy. The harmful effects of warfarin in IPF make it unclear which anticoagulant should be used for treatment of venous thromboembolism in IPF and how long anticoagulation is appropriate in patients with transient risk factors. IPF patients with venous thromboembolism are typically managed in a similar manner to patients without IPF.

\section{Sleep-disordered breathing}

Reduced sleep quality is present in most patients with IPF and is an important predictor of quality of life. ${ }^{77,78}$ The majority of IPF patients have an apnea hypopnea index of more than five events per hour, ${ }^{79-81}$ and up to $65 \%$ of IPF patients 
have an apnea hypopnea index of $>15$ that is consistent with moderate or severe OSA. ${ }^{79}$ OSA is more common in IPF than in other fibrotic ILD subtypes, ${ }^{82}$ and its severity correlates with extent of fibrosis. ${ }^{80,82}$ OSA is associated with repetitive injury to the alveolar epithelium ${ }^{83}$ and has been proposed as a potential cause of IPF. $^{84}$

Improved quality of life and sleep quality have been demonstrated in small nonrandomized studies of IPF patients with OSA who are compliant with continuous positive airway pressure (CPAP) treatment. ${ }^{79,85}$ Similar benefits were observed in the subgroup of patients without daytime sleepiness prior to initiation of CPAP. ${ }^{79}$ It may therefore be appropriate to screen all IPF patients for sleep-disordered breathing given the high prevalence of OSA in IPF $;^{79}$ the poor sensitivity of clinical features and screening tools such as the Epworth sleepiness scale; ${ }^{81}$ and the benefit of CPAP in asymptomatic patients. ${ }^{79}$ In regions with limited access to polysomnography, it is likely reasonable to screen for OSA with overnight oximetry, initiate CPAP in patients with suggestive findings, and subsequently confirm benefit through repeat overnight oximetry while on treatment. ${ }^{86}$ Patients with unclear overnight oximetry or a poor response to treatment require a more thorough assessment with polysomnography. Additional studies are required to determine the optimal screening method for sleep-disordered breathing in IPF, and to clarify the potential benefit of therapy in this population.

\section{Extra-pulmonary comorbidities Gastroesophageal reflux disease}

Gastroesophageal reflux is more common in IPF than in the general population, ${ }^{87,88}$ and markers of aspiration are elevated in bronchoalveolar lavage fluid from IPF patients compared to controls. ${ }^{88,89}$ Approximately one-third of patients with IPF have a hiatal hernia, ${ }^{90} 50 \%$ have symptoms of reflux, ${ }^{91-93}$ and up to $90 \%$ have an abnormal esophageal $\mathrm{pH}$ study. ${ }^{91,92}$ Some authors have hypothesized that microaspiration could be a cause of both IPF and acute exacerbation of IPF, ${ }^{94-96}$ suggesting that prevention of microaspiration could have an important role in the management of IPF.

Retrospective studies show that use of antiacid medication is associated with improved survival and slower disease progression in patients with IPF. ${ }^{93,97}$ Despite the absence of evidence from randomized controlled trials, antiacid therapy is recommended in recent guidelines for most IPF patients based on this potential benefit and the favorable side effect profile of antiacid medications. ${ }^{98}$ Prior fundoplication is also associated with improved survival in $\mathrm{IPF}^{93}$ and its role will be clarified by the WRAP-IPF study (NLM identifier: NCT01982968).
This multicenter randomized controlled trial will determine whether laparoscopic fundoplication surgery is superior to antiacid medication at slowing the decline of FVC in IPF patients with objectively quantified acid reflux on 24-hour $\mathrm{pH}$ monitoring. In the absence of direct data, it is reasonable to offer acid suppression medication to most IPF patients, reserving fundoplication for patients with uncontrolled symptoms and objective evidence of severe acid reflux.

\section{Coronary artery disease}

Patients with IPF are at least twice as likely to have coronary artery disease compared to control populations, even after adjusting for potential coronary risk factors. ${ }^{73,99-102}$ The majority of IPF patients have evidence of coronary atherosclerosis on chest CT or left heart catheterization, ${ }^{103}$ and significant coronary artery disease is present in up to $30 \%$ of all IPF patients. ${ }^{103-105}$ The presence of coronary artery disease is associated with increased mortality in IPF, ${ }^{103,105}$ and accounted for $10 \%$ of all deaths in a recent multicenter randomized controlled trial of pirfenidone in patients with mild to moderate IPF. ${ }^{106}$

The high morbidity and mortality of IPF limit the potential benefits of treating coronary artery disease, while risks of invasive therapies are likely higher in IPF due to worse functional capacity and respiratory status. It is therefore unknown whether IPF patients with suspected coronary artery disease should be screened and treated similarly to non-IPF patients. IPF patients should likely be evaluated for coronary artery disease if there are suggestive symptoms or CT evidence of significant atherosclerosis, particularly in the context of planned elective surgery or lung biopsy. Coronary artery calcification on chest CT has a sensitivity and specificity for left heart catheterization-confirmed disease of $81 \%$ and $85 \%$, respectively, ${ }^{104}$ suggesting a potential role of chest CT as a screening tool in at-risk patients. Standard medical therapies of coronary artery disease are likely appropriate in most IPF patients with confirmed disease; however, coronary artery stenting with drug-eluting stents may not be appropriate in some IPF patients considering that the consequent use of irreversible antiplatelet agents can complicate or potentially delay lung transplantation. Additional studies are required to determine the optimal method of screening for coronary artery disease in IPF, and whether there are specific management considerations that should apply to these patients.

\section{Depression and anxiety}

Clinically significant symptoms of depression and anxiety are present in up to $50 \%$ and $30 \%$ of IPF 
patients, respectively. ${ }^{77,107,108}$ Depression and anxiety are associated with dyspnea and other measures of fibrosis severity, ${ }^{77,107-109}$ and depression is also an important predictor of quality of life in ILD. ${ }^{109,110}$ Depressive symptoms are frequently persistent in ILD patients, ${ }^{111}$ suggesting that they are not related to an adjustment disorder that occurs only at the time of ILD diagnosis.

The high prevalence of depression and anxiety in IPF suggests that patients should be routinely questioned regarding these symptoms; however, treatments for depression and anxiety have not been studied in IPF, and most supportive evidence is extrapolated from other populations. Cognitive behavioral therapy is effective at reducing symptoms of depression and anxiety in patients with COPD. ${ }^{112,113}$ Antidepressant medications improve depression in patients with chronic physical illness, with similar benefits observed in small studies of patients with COPD. ${ }^{114} \mathrm{~A}$ recent Cochrane review highlighted the need for additional study of pharmacologic treatment of anxiety in COPD. ${ }^{115}$ The strong association of depression and anxiety with IPF symptom severity also suggests that depression and anxiety may improve with treatment of IPF itself, through interventions such as antifibrotic medication, supplemental oxygen, and pulmonary rehabilitation. ${ }^{116}$

\section{Deconditioning}

Deconditioning is defined as the loss of muscle strength and endurance due to physical inactivity. Deconditioning can exist for multiple reasons in patients with chronic lung disease, including exertional dyspnea that discourages activity and the presence of comorbidities that reduce activity through independent mechanisms. Reduced physical activity is common in IPF and COPD, ${ }^{117,118}$ and is an important predictor of mortality in healthy individuals and patients with chronic disease. ${ }^{119}$

The primary treatment of deconditioning is exercise training, which is most commonly delivered to IPF patients through structured pulmonary rehabilitation programs. Several studies have demonstrated that pulmonary rehabilitation improves physical activity and 6-minute walk distance. ${ }^{116,120-123}$ Pulmonary rehabilitation does not improve ventilatory restriction, ${ }^{121}$ and the benefits of rehabilitation are therefore primarily due to its impact on deconditioning. Future studies are needed to determine the optimal duration and format of pulmonary rehabilitation for patients with IPF and other fibrotic ILDs.

\section{Discussion}

Most patients with IPF die of progressive respiratory disease; ${ }^{106,124}$ however, the importance of identifying and managing comorbidities in IPF will increase with the use of new antifibrotic medications that slow disease progression and possibly improve survival. A number of comorbidities are common in IPF, and their importance in IPF is magnified by their cumulative symptomatic and physiologic impact on a background of chronic lung disease.

There are limited data on the management of comorbidities in patients with IPF and evidence is primarily extrapolated from COPD and other chronic lung diseases. This extrapolation is not appropriate in all patients, however, and an individualized approach to management is often necessary (Table 1). For example, long-acting betaagonists and anticholinergics primarily exert their benefits in COPD through bronchodilation and improvement in airflow limitation. Patients with CPFE are typically not flow-limited, and these treatments may therefore have less benefit in CPFE than in COPD. Similarly, it is not clear whether warfarin is the most appropriate anticoagulant for IPF patients with venous thromboembolism, given the increased mortality observed in warfarin-treated patients in a recent randomized placebo-controlled trial of patients without a specific indication for anticoagulation. ${ }^{76}$ Finally, coronary artery stenting has unique considerations for IPF patients awaiting lung transplant, given the subsequent use of irreversible antiplatelet agents with long half-lives. These examples highlight the issues with indiscriminately extrapolating findings from other populations to patients with IPF, and indicate the need for additional data on the management of comorbidities in IPF.

Comorbidities of IPF have been challenging to study for several reasons. First, IPF is a rare disease itself and each comorbidity typically affects only a fraction of these patients. Second, there is no standard approach for the definition or diagnosis of comorbid diseases in IPF. For example, studies evaluating CPFE have applied varying definitions for CPFE, differing with regards to both how radiological emphysema is quantified and how much emphysema must be present before a patient is considered to have both conditions. These inconsistencies have resulted in variable estimates of CPFE prevalence and uncertainty regarding its prognostic significance. Third, the presence of IPF can impact diagnostic accuracy. For example, the physiology of IPF impairs identification of airflow limitation that typically suggests concurrent emphysema. These challenges indicate the importance of standardized definitions and reporting structures that will facilitate the multicenter studies that are needed to study these rare populations. Such standardization would be best accomplished with the creation of prospective 
Table I Selected diagnostic and management considerations for common comorbidities of IPF

\begin{tabular}{|c|c|c|}
\hline Comorbidity & Selected screening and diagnostic considerations & Selected management considerations \\
\hline \multicolumn{3}{|c|}{ Pulmonary comorbidities } \\
\hline $\begin{array}{l}\text { Emphysema } \\
\text { (CPFE) }\end{array}$ & $\begin{array}{l}\text { - Most common in male former smokers } \\
\text { - Characterized by disproportionately reduced DLCO } \\
\text { with relatively preserved flow rates and lung volumes } \\
\text { - Frequently associated with pulmonary } \\
\text { hypertension and lung cancer }\end{array}$ & $\begin{array}{l}\text { - Similar management approach to isolated COPD } \\
\text { - Unclear role of bronchodilators in patients without flow } \\
\text { limitation } \\
\text { - Unclear role of inhaled corticosteroids } \\
\text { - Typically treat acute exacerbation with systemic } \\
\text { corticosteroids and antibiotics } \\
\text { - Rapidly taper systemic corticosteroids after an acute } \\
\text { exacerbation }\end{array}$ \\
\hline Lung cancer & $\begin{array}{l}\text { - Frequently presents with nonspecific symptoms } \\
\text { or as an incidental finding on chest imaging } \\
\text { - Low-dose CT scan screening for lung cancer } \\
\text { may have less benefit in IPF (compared to } \\
\text { mortality benefit observed in the National } \\
\text { Lung Screening Trial) }\end{array}$ & $\begin{array}{l}\text { - Increased mortality and acute exacerbation of IPF following } \\
\text { surgical resection, chemotherapy, or radiation } \\
\text { - Decrease risk of postoperative acute exacerbation of IPF } \\
\text { by reducing intravenous fluid replacement, avoiding high } \\
\text { ventilatory pressures, and minimizing hyperoxia } \\
\text { - Consider palliative therapies }\end{array}$ \\
\hline $\begin{array}{l}\text { Pulmonary } \\
\text { hypertension }\end{array}$ & $\begin{array}{l}\text { - Consider echocardiography for high-risk patients } \\
\text { - Consider right heart catheterization to confirm diagnosis } \\
\text { - Screen for other causes of pulmonary } \\
\text { hypertension in confirmed cases }\end{array}$ & $\begin{array}{l}\text { - Multiple studies show no benefit of endothelin receptor } \\
\text { antagonists in IPF with or without pulmonary hypertension } \\
\text { - Possible role for sildenafil in advanced IPF with pulmonary } \\
\text { hypertension }\end{array}$ \\
\hline $\begin{array}{l}\text { Venous } \\
\text { thromboembolism }\end{array}$ & $\begin{array}{l}\text { - Consider contrast } \mathrm{CT} \text { in patients with acute } \\
\text { respiratory worsening } \\
\text { - Isolated subsegmental filling defects are of uncertain } \\
\text { significance in severe fibrosis }\end{array}$ & $\begin{array}{l}\text { - Similar approach to management and prophylaxis compared } \\
\text { to non-IPF patients } \\
\text { - No role for anticoagulation in IPF patients that lack a } \\
\text { conventional indication }\end{array}$ \\
\hline $\begin{array}{l}\text { Sleep-disordered } \\
\text { breathing }\end{array}$ & $\begin{array}{l}\text { - Consider screening for OSA with overnight oximetry } \\
\text { or polysomnography in all IPF patients }\end{array}$ & $\begin{array}{l}\text { - Similar management approach compared to non-IPF patients } \\
\text { - CPAP may improve quality of life and sleep quality in patients } \\
\text { that do not endorse sleepiness }\end{array}$ \\
\hline \multicolumn{3}{|c|}{ Extra-pulmonary comorbidities } \\
\hline GERD & $\begin{array}{l}\text { - Asymptomatic reflux is common in IPF } \\
\text { - Unclear role of screening for acid reflux in IPF }\end{array}$ & $\begin{array}{l}\text { - Antiacid medication is recommended for most patients with } \\
\text { IPF, including those without symptoms of reflux }\end{array}$ \\
\hline $\begin{array}{l}\text { Coronary artery } \\
\text { disease }\end{array}$ & $\begin{array}{l}\text { - Coronary artery calcification on CT may be useful as } \\
\text { a screening tool }\end{array}$ & $\begin{array}{l}\text { - Similar medication approach to non-IPF patients } \\
\text { - Caution with coronary artery stenting and commitment } \\
\text { to irreversible antiplatelet agents in candidates for lung } \\
\text { transplantation }\end{array}$ \\
\hline $\begin{array}{l}\text { Depression and } \\
\text { anxiety }\end{array}$ & $\begin{array}{l}\text { - Depression is more common in patients with } \\
\text { dyspnea and severe fibrosis } \\
\text { - Screen all patients for symptoms of depression } \\
\text { and anxiety }\end{array}$ & $\begin{array}{l}\text { - Consider cognitive behavioral therapy, antidepressants, } \\
\text { and antianxiety treatments in patients with significant and } \\
\text { persistent symptoms } \\
\text { - Possible benefit of pulmonary rehabilitation }\end{array}$ \\
\hline Deconditioning & $\begin{array}{l}\text { - Screen all patients for reduced physical activity } \\
\text { levels and deconditioning }\end{array}$ & $\begin{array}{l}\text { - Consider pulmonary rehabilitation in IPF patients with } \\
\text { exertional dyspnea or functional limitation }\end{array}$ \\
\hline
\end{tabular}

Abbreviations: COPD, chronic obstructive pulmonary disease; CPAP, continuous positive airway pressure; CPFE, combined pulmonary fibrosis and emphysema; CT, computed tomography; DLCO, diffusing capacity of the lung for carbon monoxide; GERD, gastroesophageal reflux disease; IPF, idiopathic pulmonary fibrosis; OSA, obstructive sleep apnea.

multicenter registries that include prespecified definitions and reproducible diagnostic criteria for common comorbid diseases.

The concept of frailty may be useful in IPF given the simultaneous occurrence of multiple comorbidities in many patients. Frailty is defined as the cumulative impact of multiple conditions that reduce the ability of an individual to tolerate further biological stress. For example, a frail IPF patient (ie, a patient with multiple comorbidities and significant functional limitation) may be more susceptible to and intolerant of adverse effects of antifibrotic pharmacotherapy. This increased risk could prompt use of a lower medication dose or closer monitoring for significant adverse effects. Future studies are required to determine whether frailty can improve prognostication in IPF, identify patients that require additional supportive care, and risk-stratify patients who are less likely to tolerate invasive diagnostic procedures or potentially toxic pharmacotherapies. 


\section{Conclusion}

Patients with IPF are at increased risk of several comorbidities. Recent studies have provided some guidance for the management of these diseases in IPF; however, most treatment recommendations are still extrapolated from studies of nonIPF patients. Additional prospective multicenter studies are required to determine the clinical features of these comorbidities in patients with IPF and to evaluate conventional treatments and management strategies that are beneficial in non-IPF populations.

\section{Acknowledgment}

Christopher J Ryerson is supported by a Career Investigator Award from the Michael Smith Foundation for Health Research.

\section{Disclosure}

CJR has received speaking honoraria and research funding from Hoffman-La Roche Ltd and Boehringer Ingelheim. BGF reports no conflicts of interest in this work.

\section{References}

1. Raghu G, Collard HR, Egan JJ, et al. An official ATS/ERS/JRS/ALAT statement: idiopathic pulmonary fibrosis: evidence-based guidelines for diagnosis and management. Am J Respir Crit Care Med. 2011;183(6):788-824.

2. Raghu G, Weycker D, Edelsberg J, Bradford WZ, Oster G. Incidence and prevalence of idiopathic pulmonary fibrosis. Am J Respir Crit Care Med. 2006;174(7):810-816.

3. Raghu G, Chen SY, Yeh WS, et al. Idiopathic pulmonary fibrosis in US Medicare beneficiaries aged 65 years and older: incidence, prevalence, and survival, 2001-2011. Lancet Respir Med. 2014;2(7):566-572.

4. Gribbin J, Hubbard RB, Le Jeune I, Smith CJ, West J, Tata LJ. Incidence and mortality of idiopathic pulmonary fibrosis and sarcoidosis in the UK. Thorax. 2006;61(11):980-985.

5. King TE Jr, Bradford WZ, Castro-Bernardini S, et al. A phase 3 trial of pirfenidone in patients with idiopathic pulmonary fibrosis. $N$ Engl J Med. 2014;370(22):2083-2092.

6. Schmidt SL, Nambiar AM, Tayob N, et al. Pulmonary function measures predict mortality differently in IPF versus combined pulmonary fibrosis and emphysema. Eur Respir J. 2011;38(1):176-183.

7. Ryerson CJ, Hartman T, Elicker BM, et al. Clinical features and outcomes in combined pulmonary fibrosis and emphysema in idiopathic pulmonary fibrosis. Chest. 2013;144(1):234-240.

8. Akagi T, Matsumoto T, Harada T, et al. Coexistent emphysema delays the decrease of vital capacity in idiopathic pulmonary fibrosis. Respir Med. 2009;103(8):1209-1215.

9. Jankowich MD, Rounds S. Combined pulmonary fibrosis and emphysema alters physiology but has similar mortality to pulmonary fibrosis without emphysema. Lung. 2010;188(5):365-373.

10. Kurashima K, Takayanagi N, Tsuchiya N, et al. The effect of emphysema on lung function and survival in patients with idiopathic pulmonary fibrosis. Respirology. 2010;15(5):843-848.

11. Mori K, Shirai T, Mikamo M, et al. Respiratory mechanics measured by forced oscillation technique in combined pulmonary fibrosis and emphysema. Respir Physiol Neurobiol. 2013;185(2):235-240.

12. Mura M, Zompatori M, Pacilli AM, Fasano L, Schiavina M, Fabbri M. The presence of emphysema further impairs physiologic function in patients with idiopathic pulmonary fibrosis. Respir Care. 2006;51(3): 257-265.
13. Tasaka S, Mizoguchi K, Funatsu Y, et al. Cytokine profile of bronchoalveolar lavage fluid in patients with combined pulmonary fibrosis and emphysema. Respirology. 2012;17(5):814-820.

14. Todd NW, Jeudy J, Lavania S, et al. Centrilobular emphysema combined with pulmonary fibrosis results in improved survival. Fibrogenesis Tissue Repair. 2011;4(1):6.

15. Mejia M, Carrillo G, Rojas-Serrano J, et al. Idiopathic pulmonary fibrosis and emphysema: decreased survival associated with severe pulmonary arterial hypertension. Chest. 2009;136(1):10-15.

16. Sugino K, Ishida F, Kikuchi N, et al. Comparison of clinical characteristics and prognostic factors of combined pulmonary fibrosis and emphysema versus idiopathic pulmonary fibrosis alone. Respirology. 2014;19(2):239-245.

17. Cottin V, Nunes H, Brillet PY, et al. Combined pulmonary fibrosis and emphysema: a distinct underrecognised entity. Eur Respir J. 2005;26(4):586-593.

18. Antoniou KM, Walsh SL, Hansell DM, et al. Smoking-related emphysema is associated with idiopathic pulmonary fibrosis and rheumatoid lung. Respirology. 2013;18(8):1191-1196.

19. Kishaba T, Shimaoka Y, Fukuyama H, et al. A cohort study of mortality predictors and characteristics of patients with combined pulmonary fibrosis and emphysema. BMJ Open. 2012;2(3).

20. Kitaguchi Y, Fujimoto K, Hanaoka M, Kawakami S, Honda T, Kubo $\mathrm{K}$. Clinical characteristics of combined pulmonary fibrosis and emphysema. Respirology. 2010;15(2):265-271.

21. Lee CH, Kim HJ, Park CM, et al. The impact of combined pulmonary fibrosis and emphysema on mortality. Int J Tuberc Lung Dis. 2011; 15(8):1111-1116.

22. Kew KM, Seniukovich A. Inhaled steroids and risk of pneumonia for chronic obstructive pulmonary disease. Cochrane Database Syst Rev. 2014;3:CD010115.

23. Idiopathic Pulmonary Fibrosis Clinical Research Network, Raghu G, Anstrom KJ, King TE Jr, Lasky JA, Martinez FJ. Prednisone, azathioprine, and $\mathrm{N}$-acetylcysteine for pulmonary fibrosis. $N$ Engl J Med. 2012;366(21):1968-1977.

24. Hubbard R, Venn A, Lewis S, Britton J. Lung cancer and cryptogenic fibrosing alveolitis. A population-based cohort study. Am J Respir Crit Care Med. 2000;161(1):5-8.

25. Tomassetti S, Gurioli C, Ryu JH, et al. The impact of lung cancer on survival of idiopathic pulmonary fibrosis. Chest. 2015;147(1): $157-164$.

26. National Lung Screening Trial Research Team, Aberle DR, Adams AM, et al. Reduced lung-cancer mortality with low-dose computed tomographic screening. N Engl J Med. 2011;365(5):395-409.

27. Detterbeck FC, Mazzone PJ, Naidich DP, Bach PB. Screening for lung cancer: Diagnosis and management of lung cancer, 3rd ed: American College of Chest Physicians evidence-based clinical practice guidelines. Chest. 2013;143(5 Suppl):e78S-e92S.

28. Kumar P, Goldstraw P, Yamada K, et al. Pulmonary fibrosis and lung cancer: risk and benefit analysis of pulmonary resection. $J$ Thorac Cardiovasc Surg. 2003;125(6):1321-1327.

29. Mizuno Y, Iwata H, Shirahashi K, et al. The importance of intraoperative fluid balance for the prevention of postoperative acute exacerbation of idiopathic pulmonary fibrosis after pulmonary resection for primary lung cancer. Eur J Cardiothorac Surg. 2012;41(6):e161-e165.

30. Sakamoto S, Homma S, Mun M, Fujii T, Kurosaki A, Yoshimura K. Acute exacerbation of idiopathic interstitial pneumonia following lung surgery in 3 of 68 consecutive patients: a retrospective study. Intern Med. 2011;50(2):77-85.

31. Suzuki H, Sekine Y, Yoshida S, et al. Risk of acute exacerbation of interstitial pneumonia after pulmonary resection for lung cancer in patients with idiopathic pulmonary fibrosis based on preoperative high-resolution computed tomography. Surg Today. 2011;41(7): 914-921.

32. Sugiura H, Takeda A, Hoshi T, et al. Acute exacerbation of usual interstitial pneumonia after resection of lung cancer. Ann Thorac Surg. 2012;93(3):937-943. 
33. Shintani Y, Ohta M, Iwasaki T, et al. Predictive factors for postoperative acute exacerbation of interstitial pneumonia combined with lung cancer. Gen Thorac Cardiovasc Surg. 2010;58(4):182-185.

34. Perez-Alvarez R, Perez-de-Lis M, Diaz-Lagares C, et al. Interstitial lung disease induced or exacerbated by TNF-targeted therapies: analysis of 122 cases. Semin Arthritis Rheum. 2011;41(2):256-264.

35. Takeda A, Enomoto T, Sanuki N, et al. Acute exacerbation of subclinical idiopathic pulmonary fibrosis triggered by hypofractionated stereotactic body radiotherapy in a patient with primary lung cancer and slightly focal honeycombing. Radiat Med. 2008;26(8):504-507.

36. Kenmotsu H, Naito T, Kimura M, et al. The risk of cytotoxic chemotherapy-related exacerbation of interstitial lung disease with lung cancer. J Thorac Oncol. 2011;6(7):1242-1246.

37. Shorr AF, Wainright JL, Cors CS, Lettieri CJ, Nathan SD. Pulmonary hypertension in patients with pulmonary fibrosis awaiting lung transplant. Eur Respir J. 2007;30(4):715-721.

38. Nathan SD, Shlobin OA, Ahmad S, Urbanek S, Barnett SD. Pulmonary hypertension and pulmonary function testing in idiopathic pulmonary fibrosis. Chest. 2007;131(3):657-663.

39. Modrykamien AM, Gudavalli R, McCarthy K, Parambil J. Echocardiography, 6-minute walk distance, and distance-saturation product as predictors of pulmonary arterial hypertension in idiopathic pulmonary fibrosis. Respir Care. 2010;55(5):584-588.

40. Lettieri CJ, Nathan SD, Barnett SD, Ahmad S, Shorr AF. Prevalence and outcomes of pulmonary arterial hypertension in advanced idiopathic pulmonary fibrosis. Chest. 2006;129(3):746-752.

41. Boutou AK, Pitsiou GG, Trigonis I, et al. Exercise capacity in idiopathic pulmonary fibrosis: the effect of pulmonary hypertension. Respirology. 2011;16(3):451-458.

42. Corte TJ, Wort SJ, Gatzoulis MA, Macdonald P, Hansell DM, Wells AU. Pulmonary vascular resistance predicts early mortality in patients with diffuse fibrotic lung disease and suspected pulmonary hypertension. Thorax. 2009;64(10):883-888.

43. Salajka F, Bartos V, Novosad J, et al. Failure of noninvasive prediction of pulmonary hypertension in patients with idiopathic pulmonary fibrosis. Monaldi Arch Chest Dis. 2011;75(3):172-177.

44. Nathan SD, Shlobin OA, Barnett SD, et al. Right ventricular systolic pressure by echocardiography as a predictor of pulmonary hypertension in idiopathic pulmonary fibrosis. Respir Med. 2008;102(9): 1305-1310.

45. Zisman DA, Ross DJ, Belperio JA, et al. Prediction of pulmonary hypertension in idiopathic pulmonary fibrosis. Respir Med. 2007;101(10): 2153-2159.

46. Zisman DA, Karlamangla AS, Kawut SM, et al. Validation of a method to screen for pulmonary hypertension in advanced idiopathic pulmonary fibrosis. Chest. 2008;133(3):640-645.

47. Minai OA, Santacruz JF, Alster JM, Budev MM, McCarthy K. Impact of pulmonary hemodynamics on 6-min walk test in idiopathic pulmonary fibrosis. Respir Med. 2012;106(11):1613-1621.

48. Papakosta D, Pitsiou G, Daniil Z, et al. Prevalence of pulmonary hypertension in patients with idiopathic pulmonary fibrosis: correlation with physiological parameters. Lung. 2011;189(5):391-399.

49. Andersen CU, Mellemkjær S, Hilberg O, Nielsen-Kudsk JE, Simonsen U, Bendstrup E. Pulmonary hypertension in interstitial lung disease: prevalence, prognosis and 6 min walk test. Respir Med. 2012;106(6): 875-882.

50. Swigris JJ, Olson AL, Shlobin OA, Ahmad S, Brown KK, Nathan SD. Heart rate recovery after six-minute walk test predicts pulmonary hypertension in patients with idiopathic pulmonary fibrosis. Respirology. 2011;16(3):439-445.

51. Swigris JJ, Swick J, Wamboldt FS, et al. Heart rate recovery after 6-min walk test predicts survival in patients with idiopathic pulmonary fibrosis. Chest. 2009;136(3):841-848.

52. Arcasoy SM, Christie JD, Ferrari VA, et al. Echocardiographic assessment of pulmonary hypertension in patients with advanced lung disease. Am J Respir Crit Care Med. 2003;167(5):735-740.

53. Hamada K, Nagai S, Tanaka S, et al. Significance of pulmonary arterial pressure and diffusion capacity of the lung as prognosticator in patients with idiopathic pulmonary fibrosis. Chest. 2007;131(3):650-656.
54. Judge EP, Fabre A, Adamali HI, Egan JJ. Acute exacerbations and pulmonary hypertension in advanced idiopathic pulmonary fibrosis. Eur Respir J. 2012;40(1):93-100.

55. Song JW, Song JK, Kim DS. Echocardiography and brain natriuretic peptide as prognostic indicators in idiopathic pulmonary fibrosis. Respir Med. 2009;103(2):180-186.

56. Nadrous HF, Pellikka PA, Krowka MJ, et al. Pulmonary hypertension in patients with idiopathic pulmonary fibrosis. Chest. 2005;128(4): 2393-2399.

57. Kimura M, Taniguchi H, Kondoh Y, et al. Pulmonary hypertension as a prognostic indicator at the initial evaluation in idiopathic pulmonary fibrosis. Respiration. 2013;85(6):456-463.

58. Gläser S, Obst A, Koch B, et al. Pulmonary hypertension in patients with idiopathic pulmonary fibrosis - the predictive value of exercise capacity and gas exchange efficiency. PloS One. 2013;8(6):e65643.

59. Rivera-Lebron BN, Forfia PR, Kreider M, Lee JC, Holmes JH, Kawut SM. Echocardiographic and hemodynamic predictors of mortality in idiopathic pulmonary fibrosis. Chest. 2013;144(2):564-570.

60. Raghu G, Behr J, Brown KK, et al. Treatment of idiopathic pulmonary fibrosis with ambrisentan: a parallel, randomized trial. Ann Intern Med. 2013;158(9):641-649.

61. Raghu G, Million-Rousseau R, Morganti A, Perchenet L, Behr J; MUSIC Study Group. Macitentan for the treatment of idiopathic pulmonary fibrosis: the randomised controlled MUSIC trial. Eur Respir J. 2013;42(6):1622-1632.

62. King TE Jr, Behr J, Brown KK, et al. BUILD-1: a randomized placebocontrolled trial of bosentan in idiopathic pulmonary fibrosis. Am J Respir Crit Care Med. 2008;177(1):75-81.

63. King TE Jr, Brown KK, Raghu G, et al. BUILD-3: a randomized, controlled trial of bosentan in idiopathic pulmonary fibrosis. Am J Respir Crit Care Med. 2011;184(1):92-99.

64. Corte TJ, Keir GJ, Dimopoulos K, et al. Bosentan in pulmonary hypertension associated with fibrotic idiopathic interstitial pneumonia. Am J Respir Crit Care Med. 2014;190(2):208-217.

65. Idiopathic Pulmonary Fibrosis Clinical Research Network, Zisman DA, Schwarz M, et al. A controlled trial of sildenafil in advanced idiopathic pulmonary fibrosis. N Engl J Med. 2010;363(7):620-628.

66. Han MK, Bach DS, Hagan PG, et al. Sildenafil preserves exercise capacity in patients with idiopathic pulmonary fibrosis and right-sided ventricular dysfunction. Chest. 2013;143(6):1699-1708.

67. Wallaert B, Monge E, Le Rouzic O, Wémeau-Stervinou L, Salleron J, Grosbois JM. Physical activity in daily life of patients with fibrotic idiopathic interstitial pneumonia. Chest. 2013;144(5):1652-1658.

68. Kotani I, Sato A, Hayakawa H, Urano T, Takada Y, Takada A. Increased procoagulant and antifibrinolytic activities in the lungs with idiopathic pulmonary fibrosis. Thromb Res. 1995;77(6):493-504.

69. Günther A, Mosavi P, Ruppert C, et al. Enhanced tissue factor pathway activity and fibrin turnover in the alveolar compartment of patients with interstitial lung disease. Thromb Haemost. 2000;83(6):853-860.

70. Sprunger DB, Olson AL, Huie TJ, et al. Pulmonary fibrosis is associated with an elevated risk of thromboembolic disease. Eur Respir J. 2012;39(1):125-132.

71. Sode BF, Dahl M, Nielsen SF, Nordestgaard BG. Venous thromboembolism and risk of idiopathic interstitial pneumonia: a nationwide study. Am J Respir Crit Care Med. 2010;181(10):1085-1092.

72. Dalleywater W, Powell HA, Fogarty AW, Hubbard RB, Navaratnam V. Venous thromboembolism in people with idiopathic pulmonary fibrosis: a population-based study. Eur Respir J. 2014;44(6):1714-1715.

73. Hubbard RB, Smith C, Le Jeune I, Gribbin J, Fogarty AW. The association between idiopathic pulmonary fibrosis and vascular disease: a populationbased study. Am J Respir Crit Care Med. 2008;178(12): 1257-1261.

74. Kubo H, Nakayama K, Yanai M, et al. Anticoagulant therapy for idiopathic pulmonary fibrosis. Chest. 2005;128(3):1475-1482.

75. Kinder BW, Collard HR, King TE Jr. Anticoagulant therapy and idiopathic pulmonary fibrosis. Chest. 2006;130(1):302-303.

76. Noth I, Anstrom KJ, Calvert SB, et al. A placebo-controlled randomized trial of warfarin in idiopathic pulmonary fibrosis. Am J Respir Crit Care Med. 2012;186(1):88-95. 
77. Ryerson CJ, Berkeley J, Carrieri-Kohlman VL, Pantilat SZ, Landefeld CS, Collard HR. Depression and functional status are strongly associated with dyspnea in interstitial lung disease. Chest. 2011;139(3): 609-616.

78. Krishnan V, McCormack MC, Mathai SC, et al. Sleep quality and health-related quality of life in idiopathic pulmonary fibrosis. Chest. 2008;134(4):693-698.

79. Mermigkis C, Bouloukaki I, Antoniou K, et al. Obstructive sleep apnea should be treated in patients with idiopathic pulmonary fibrosis. Sleep Breath. 2015;19(1):385-391.

80. Mermigkis C, Stagaki E, Tryfon S, et al. How common is sleepdisordered breathing in patients with idiopathic pulmonary fibrosis? Sleep Breath. 2010;14(4):387-390.

81. Lancaster LH, Mason WR, Parnell JA, et al. Obstructive sleep apnea is common in idiopathic pulmonary fibrosis. Chest. 2009;136(3): 772-778.

82. Pihtili A, Bingol Z, Kiyan E, Cuhadaroglu C, Issever H, Gulbaran Z. Obstructive sleep apnea is common in patients with interstitial lung disease. Sleep Breath. 2013;17(4):1281-1288.

83. Lederer DJ, Jelic S, Basner RC, Ishizaka A, Bhattacharya J. Circulating KL-6, a biomarker of lung injury, in obstructive sleep apnoea. Eur Respir J. 2009;33(4):793-796.

84. Lederer DJ, Jelic S, Bhattacharya J, Basner RC. Is obstructive sleep apnea a cause of idiopathic pulmonary fibrosis? Arch Pathol Lab Med. 2012;136(5):470; author reply 470.

85. Mermigkis C, Bouloukaki I, Antoniou KM, et al. CPAP therapy in patients with idiopathic pulmonary fibrosis and obstructive sleep apnea: does it offer a better quality of life and sleep? Sleep Breath. 2013;17(4): 1137-1143.

86. Mulgrew AT, Fox N, Ayas NT, Ryan CF. Diagnosis and initial management of obstructive sleep apnea without polysomnography: a randomized validation study. Ann Intern Med. 2007;146(3):157-166.

87. Fahim A, Dettmar PW, Morice AH, Hart SP. Gastroesophageal reflux and idiopathic pulmonary fibrosis: a prospective study. Medicina (Kaunas). 2011;47(4):200-205.

88. Savarino E, Carbone R, Marabotto E, et al. Gastro-oesophageal reflux and gastric aspiration in idiopathic pulmonary fibrosis patients. Eur Respir J. 2013;42(5):1322-1331.

89. Lozo Vukovac E, Lozo M, Mise K, et al. Bronchoalveolar $\mathrm{pH}$ and inflammatory biomarkers in newly diagnosed IPF and GERD patients: a case-control study. Med Sci Monit. 2014;20:255-261.

90. Noth I, Zangan SM, Soares RV, et al. Prevalence of hiatal hernia by blinded multidetector CT in patients with idiopathic pulmonary fibrosis. Eur Respir J. 2012;39(2):344-351.

91. Raghu G, Freudenberger TD, Yang S, et al. High prevalence of abnormal acid gastro-oesophageal reflux in idiopathic pulmonary fibrosis. Eur Respir J. 2006;27(1):136-142.

92. Sweet MP, Patti MG, Leard LE, et al. Gastroesophageal reflux in patients with idiopathic pulmonary fibrosis referred for lung transplantation. J Thorac Cardiovasc Surg. 2007;133(4):1078-1084.

93. Lee JS, Ryu JH, Elicker BM, et al. Gastroesophageal reflux therapy is associated with longer survival in patients with idiopathic pulmonary fibrosis. Am J Respir Crit Care Med. 2011;184(12):1390-1394.

94. Lee JS, Song JW, Wolters PJ, et al. Bronchoalveolar lavage pepsin in acute exacerbation of idiopathic pulmonary fibrosis. Eur Respir $J$ 2012;39(2):352-358.

95. Tcherakian C, Cottin V, Brillet PY, et al. Progression of idiopathic pulmonary fibrosis: lessons from asymmetrical disease. Thorax. 2011;66(3):226-231.

96. Lee JS, Collard HR, Raghu G, et al. Does chronic microaspiration cause idiopathic pulmonary fibrosis? Am J Med. 2010;123(4):304-311.

97. Lee JS, Collard HR, Anstrom KJ, et al. Anti-acid treatment and disease progression in idiopathic pulmonary fibrosis: an analysis of data from three randomised controlled trials. Lancet Respir Med. 2013;1(5):369-376.

98. Raghu G, Rochwerg B, Zhang Y, et al. An Official ATS/ERS/JRS/ALAT Clinical Practice Guideline: Treatment of Idiopathic Pulmonary Fibrosis. An Update of the 2011 Clinical Practice Guideline. Am J Respir Crit Care Med. 2015;192(2):e3-e19.
99. Kizer JR, Zisman DA, Blumenthal NP, et al. Association between pulmonary fibrosis and coronary artery disease. Arch Intern Med. 2004;164(5):551-556.

100. Kim WY, Mok Y, Kim GW, et al. Association between idiopathic pulmonary fibrosis and coronary artery disease: a case-control study and cohort analysis. Sarcoidosis Vasc Diffuse Lung Dis. 2015;31(4): 289-296.

101. Dalleywater W, Powell HA, Hubbard RB, Navaratnam V. Risk factors for cardiovascular disease in people with idiopathic pulmonary fibrosis: a population-based study. Chest. 2015;147(1):150-156.

102. Ponnuswamy A, Manikandan R, Sabetpour A, Keeping IM, Finnerty JP. Association between ischaemic heart disease and interstitial lung disease: a case-control study. Respir Med. 2009;103(4): 503-507

103. Nathan SD, Basavaraj A, Reichner C, et al. Prevalence and impact of coronary artery disease in idiopathic pulmonary fibrosis. Respir Med. 2010;104(7):1035-1041.

104. Nathan SD, Weir N, Shlobin OA, et al. The value of computed tomography scanning for the detection of coronary artery disease in patients with idiopathic pulmonary fibrosis. Respirology. 2011; 16(3):481-486.

105. Hyldgaard C, Hilberg O, Bendstrup E. How does comorbidity influence survival in idiopathic pulmonary fibrosis? Respir Med. 2014; 108(4):647-653.

106. King TE Jr, Albera C, Bradford WZ, et al. All-cause mortality rate in patients with idiopathic pulmonary fibrosis. Implications for the design and execution of clinical trials. Am J Respir Crit Care Med. 2014;189(7):825-831.

107. Akhtar AA, Ali MA, Smith RP. Depression in patients with idiopathic pulmonary fibrosis. Chron Respir Dis. 2013;10(3):127-133.

108. Holland AE, Fiore JF Jr, Bell EC, et al. Dyspnoea and comorbidity contribute to anxiety and depression in interstitial lung disease. Respirology. 2014;19(8):1215-1221.

109. De Vries J, Kessels BL, Drent M. Quality of life of idiopathic pulmonary fibrosis patients. Eur Respir J. 2001;17(5):954-961.

110. Elfferich MD, De Vries J, Drent M. Type D or 'distressed' personality in sarcoidosis and idiopathic pulmonary fibrosis. Sarcoidosis Vasc Diffuse Lung Dis. 2011;28(1):65-71.

111. Ryerson CJ, Arean PA, Berkeley J, et al. Depression is a common and chronic comorbidity in patients with interstitial lung disease. Respirology. 2012;17(3):525-532.

112. Lamers F, Jonkers CC, Bosma H, Chavannes NH, Knottnerus JA, van Eijk JT. Improving quality of life in depressed COPD patients: effectiveness of a minimal psychological intervention. COPD 2010;7(5):315-322.

113. Kunik ME, Veazey C, Cully JA, et al. COPD education and cognitive behavioral therapy group treatment for clinically significant symptoms of depression and anxiety in COPD patients: a randomized controlled trial. Psychol Med. 2008;38(3):385-396.

114. Rayner L, Price A, Evans A, Valsraj K, Higginson IJ, Hotopf M. Antidepressants for depression in physically ill people. Cochrane Database Syst Rev. 2010;(3):CD007503.

115. Usmani ZA, Carson KV, Cheng JN, Esterman AJ, Smith BJ. Pharmacological interventions for the treatment of anxiety disorders in chronic obstructive pulmonary disease. Cochrane Database Syst Rev. 2011;(11):CD008483.

116. Ryerson CJ, Cayou C, Topp F, et al. Pulmonary rehabilitation improves long-term outcomes in interstitial lung disease: a prospective cohort study. Respir Med. 2014;108(1):203-210.

117. Nakayama M, Bando M, Araki K, et al. Physical activity in patients with idiopathic pulmonary fibrosis. Respirology. 2015;20(4):640-646.

118. Pitta F, Troosters T, Spruit MA, Probst VS, Decramer M, Gosselink R. Characteristics of physical activities in daily life in chronic obstructive pulmonary disease. Am J Respir Crit Care Med. 2005;171(9): 972-977.

119. Paffenbarger RS Jr, Hyde RT, Wing AL, Hsieh CC. Physical activity, all-cause mortality, and longevity of college alumni. $N$ Engl J Med. 1986;314(10):605-613. 
120. Gaunaurd IA, Gómez-Marín OW, Ramos CF, et al. Physical activity and quality of life improvements of patients with idiopathic pulmonary fibrosis completing a pulmonary rehabilitation program. Respir Care. 2014;59(12):1872-1879.

121. Holland AE, Hill CJ, Conron M, Munro P, McDonald CF. Short term improvement in exercise capacity and symptoms following exercise training in interstitial lung disease. Thorax. 2008;63(6):549-554.

122. Swigris JJ, Fairclough DL, Morrison M, et al. Benefits of pulmonary rehabilitation in idiopathic pulmonary fibrosis. Respir Care. 2011;56(6):783-789.
123. Nishiyama O, Kondoh Y, Kimura T, et al. Effects of pulmonary rehabilitation in patients with idiopathic pulmonary fibrosis. Respirology. 2008;13(3):394-399.

124. Martinez FJ, Safrin S, Weycker D, et al. The clinical course of patients with idiopathic pulmonary fibrosis. Ann Intern Med. 2005;142(12 Pt 1): 963-967.

\section{Publish your work in this journal}

The International Journal of General Medicine is an international, peer-reviewed open-access journal that focuses on general and internal medicine, pathogenesis, epidemiology, diagnosis, monitoring and treatment protocols. The journal is characterized by the rapid reporting of reviews, original research and clinical studies across all disease areas.
A key focus is the elucidation of disease processes and management protocols resulting in improved outcomes for the patient. The manuscript management system is completely online and includes a very quick and fair peer-review system. Visit http://www.dovepress.com/ testimonials.php to read real quotes from published authors.

Submit your manuscript here: http://www.dovepress.com/international-journal-of-general-medicine-journal 